\title{
Negação não psicótica da gravidez: definições, especificidades e explicações
}

\section{Non psychotic denial of pregnancy: definitions, characteristics and explanations}

\section{Negación no psicótica del embarazo: definiciónes, características y explicaciones}

\section{Thomás Gomes Gonçalves*}

Universidade Federal do Rio Grande do Sul - UFRGS, Porto Alegre, Rio Grande do Sul, Brasil

\begin{abstract}
RESUMO
O objetivo desta revisão da literatura PSI é contribuir para a produção de conhecimento sobre o fenômeno da negação não psicótica da gravidez, tendo em vista a pouca produção científica nacional. Tal situação consiste no fato de uma mulher passar boa parte da gestação, ou até no momento do parto, sem saber que está gravida. Para tanto, buscaram-se em bancos de dados nacionais e internacionais, além de encontros presenciais com profissionais que trabalham com esse tema, as pesquisas já realizadas e os aspectos sobre o fenômeno que precisam ser ainda aprofundados e abordados para que se possa ter um avanço científico em relação à compreensão dessa experiência.
\end{abstract}

Palavras-chave: negação não psicótica da gravidez, gravidez, situação materno-infantil de risco.

\begin{abstract}
The objective of this literature review is to provide information about the phenomenon of non-psychotic denial of pregnancy, given the lack of national scientific studies. This situation happens when a woman spends most part of pregnancy or until labor without knowing that she is pregnant. Thus, it is was search in national and international databases, as well as encounters conducted with professional who work on this topic, the researches already performed and which aspects about the phenomenon need to be more understood and addressed in order to have a scientific advance related to this experience.
\end{abstract}

Keywords: non-psychotic denial of pregnancy, pregnancy, mother-child risk situation.

\section{RESUMEN}

El objetivo de esa revisión de literatura es contribuir para la producción de conocimiento sobre el fenómeno de la negación no psicótica del embarazo, en vista de la poca producción científica nacional. Tal situación consiste en el hecho de una mujer pasar al largo del embarazo o hasta el momento del parto sin saber que está embarazada. Por lo tanto, se buscaran en bases de 
datos nacionales e internacionales, así como encuentros presenciales con profesionales que trabajan en ese tema, las investigaciones ya hechas y cuales aspectos sobre el fenómeno que necesitan ser aún profundizados y abordados para que se pueda suceder un avanzo científico en relación a la comprensión de esa experiencia.

Palabras-clave: negación no psicótica del embarazo, embarazo, situación materno-infantil de riesgo.

\section{Introdução}

Diversos estudos têm explorado a experiência de gestação a partir de diferentes áreas do Saber. Na Psicologia, percebe-se que as pesquisas têm investigado as implicações que a gravidez acarreta tanto na vida da própria gestante quanto na relação com o seu filho recém-nascido, seja em contextos de saúde ou psicopatológicos. Além disso, destaca-se que os estudos que discorrem sobre esse tema partem do pressuposto de o estado gravídico ser um processo consciente. No entanto, outras pesquisas demonstram que a gravidez pode permanecer sem ser percebida pela própria gestante, transcorrendo, dessa forma, inconscientemente. Tal descrição tem sido nomeada na literatura científica como negação não psicótica da gravidez.

O presente estudo tem como objetivo apresentar uma revisão de literatura sobre publicações relacionadas à situação de negação não psicótica da gravidez. Para tanto, foi realizada uma pesquisa nas principais bases de dados nacionais e internacionais (PsycINFO, PubMed, SAGE, Periódicos Capes, LILACS, PePSIC e SciELO), no período compreendido de 1993 a 2013, utilizando os descritores denial of pregnancy, pregnancy denied e unknown pregnancy. Ressalta-se que alguns dos trabalhos incluídos no presente estudo não resultaram da pesquisa realizada nas bases de dados. Eles foram rastreados a partir das referências bibliográficas das produções obtidas nessa pesquisa. Obras de referência sobre o fenômeno também foram incluídas. Ademais, adicionaram-se informações obtidas por meio de encontros presenciais com profissionais que se dedicam a esse tema.

A partir do material bibliográfico coletado, percebe-se a pouca produção científica em relação à negação não psicótica da gravidez. Os estudos são em sua maioria oriundos do hemisfério norte, sendo escassas as publicações nacionais. Os artigos brasileiros encontrados não contam com uma revisão de literatura aprofundada e abrangente. Nessa direção, objetiva-se a apresentação de uma revisão de literatura que contemple os mais diversos aspectos sobre o fenômeno, com o intuito de discutir os estudos existentes. Pretende-se, assim, detectar lacunas na literatura específica que possam vir a colaborar para um avanço científico sobre o tema. 


\section{0 fenômeno da negação da gravidez através da história}

Em 1681, o ginecologista François Mauriceau afirmou que a ocorrência de um ciclo menstrual irregular poderia levar certas mulheres a ignorar o próprio estado gravídico (Chaulet, 2011). Em 1858, o psiquiatra Louis-Victor Marcé constatou que algumas gestantes hospitalizadas por episódios maníacos ou melancólicos poderiam não ter a consciência de estarem grávidas. Em 1865, o Dictionnaire Encyclopédique des Sciences Médicales dedicou alguns capítulos a partir de uma perspectiva médico-legal sobre situações de gestações desconhecidas. Nove anos depois, o médico legista e criminologista Auguste-Ambroise Tardieu investigou casos de mulheres que matavam seus filhos após o parto por não saberem que estavam grávidas. Tardieu acreditava que essas mulheres, em verdade, dissimulavam o processo gestacional (Grangaud, 2001).

Quase na virada do século XX, em 1898, o médico George Gould esboça uma primeira tentativa de formular uma entidade clínica para a negação da gravidez cunhando o termo gravidez inconsciente (Chaulet, 2011; Grangaud, 2001). Dois anos depois, Paul Brouardel, médico legista, escreveu um capítulo intitulado "Une femme peutelle être enceinte à son insu?" (Pode uma mulher estar grávida sem o seu conhecimento?). Brouardel afirmou, ao longo do texto, que as únicas duas possibilidades de uma mulher não saber acerca de sua própria gestação se refeririam a casos de mulheres que passaram por algum tipo de erro médico no diagnóstico ou a de mulheres que eram loucas, "folles". Os casos apresentados por Brouardel são os primeiros a retratar a negação da gravidez em mulheres com um bom nível social (Chaulet, 2011; Seguin, 2011).

Ao investigar historicamente o fenômeno da negação não psicótica da gravidez, pode-se verificar que, desde os primeiros registros até a contribuição de Brouardel, em 1900, o fenômeno era entendido como oriundo de alguma patologia mental, como um caso em que a gravidez fora propositalmente dissimulada pela mulher ou advindo de um erro médico. Assim, o fenômeno até então não era compreendido como uma situação em que uma mulher sem um diagnóstico de alguma psicopatologia poderia efetivamente não saber que estava grávida.

No entanto, as primeiras contribuições do século $X X$, além de mostrar que era possível uma gravidez transcorrer sem o conhecimento da gestante, contribuíram também para a distinção entre situações em que os componentes próprios da psicose (alucinações e delírio) se mostram presentes ou ausentes. Nessa direção, em 1957, o médico J. Gerchow ressaltou que uma característica dos estados gravídicos que são desconhecidos à própria mulher, é a pouca mudança 
morfológica e fisiológica (Chaulet, 2011). No ano de 1970, é cunhado o termo déni de grossesse (negação da gravidez), que foi utilizado para se referir a casos de esquizofrenia (Slayton \& Soloff, 1981). Já os estudos dos anos 1980 e 1990 passaram a destacar diferentes tipos de negação da gravidez: uma situação em que mulheres com diagnóstico de psicose negam a gestação, outra em que mulheres negam a gravidez, porém não possuem sintomatologia e diagnóstico de psicose, e, ainda, um outro tipo, em que a mulher sabe que está grávida, mas finge e dissimula o processo gestacional (Bonnet, 1993; Kaplan \& Grotowski, 1996; Milstein \& Milstein, 1983). Desse modo, a negação não psicótica da gravidez não foi mais confundida como oriunda de uma experiência de ruptura com a realidade ou com uma situação de dissimulação da gravidez.

$\mathrm{Na}$ esteira desse movimento, em 1988, é escrita a primeira tese de doutorado (Labarthe, 1988), e, em 1995, a primeira pesquisa epidemiológica (Wessel, Endrikat, \& Buscher, 2002) especificamente sobre a negação não psicótica da gravidez. Ademais, criou-se, no ano de 2003, a Association Française pour le Reconnaissance du Déni de Grossesse (AFRDG), primeira e única associação científica no mundo se dedicar a esse tipo de negação da gravidez.

Em 2006, houve a tentativa de incluir este fenômeno no Manual Diagnóstico e Estatístico de Transtornos Mentais (DSM) e no Código Internacional de Doenças (CID), em uma nova categoria para disfunções reprodutivas sem causa orgânica (Beier, Wille, \& Wessel, 2006). No entanto, na última edição do DSM-V, tal fenômeno não foi incluído. Essa tentativa de inclusão da negação não psicótica da gravidez, tanto no DSM quanto no CID, indica um retorno ao entendimento de que esse fenômeno seja pertencente à esfera da psicopatologia, como antes visto, nos primeiros registros históricos.

Por outro lado, as pesquisas sobre o fenômeno em outras áreas do saber, como na medicina, vêm sendo desenvolvidas na busca de ampliação de sua compreensão. Conforme J.Wessel (Comunicação pessoal, 16 de julho de 2013), está sendo realizada uma pesquisa epidemiológica na Turquia com o objetivo de saber quantas mulheres em um ano não souberam que estavam grávidas. Em 2014, foi defendida a primeira dissertação de mestrado sobre o fenômeno no Brasil, sendo a primeira pesquisa sobre o tema desenvolvida na América Latina. A partir de uma perspectiva psicanalítica, tal investigação procurou compreender implicações psíquicas de mulheres que passaram por essa experiência (Gonçalves, 2014).

\section{Os diferentes tipos de negação da gravidez}

A partir do material coletado para esta revisão de literatura PSI e do que foi ressaltado anteriormente por meio da investigação histórica, é 
possível constatar que a literatura apresenta três diferentes tipos de negação da gravidez. Nessa direção, Miller (2003) propõe diferentes nomenclaturas para os tipos de negação da gravidez: affective denial (negação afetiva), pervasive denial (negação invasiva) e psychotic denial (negação psicótica). O primeiro, a 'negação afetiva', se refere à situação em que uma mulher sabe e reconhece que está grávida, porém não se envolve emocionalmente com a gestação e tampouco realiza alguma mudança emocional ou comportamental para tal experiência. O segundo tipo proposto por Miller (2003), a 'negação invasiva', diz respeito a uma forma mais extrema de negação em que a gestação permanece afastada da consciência, podendo levar uma mulher a descobrir que está grávida somente na hora do parto. As mudanças corporais são quase ausentes e quando, todavia, ocorrem, são comumente interpretadas ou atribuídas a outras questões: a amenorreia pode ser considerada como advinda da menopausa ou de um evento estressante e os movimentos fetais podem ser interpretados como gases intestinais. É comum, também, que, mesmo após terem tido o filho, certas mulheres possam continuar a negar que estiveram grávidas. Já no terceiro tipo, de 'negação psicótica', as mudanças no corpo são visíveis e os sintomas de uma gestação ocorrem normalmente, porém, pelo estado debilitado em que se encontra a gestante, os sintomas são interpretados a partir de algum componente delirante (Miller, 2003).

Chaulet (2011) propõe entender o fenômeno da seguinte forma: déni psychotique de grossesse - negação psicótica, na qual há a presença de esquizofrenia evolutiva; déni de grossesse (non psychotique) negação não psicótica da gravidez, situação em que há ausência de tal psicopatologia. A forma não psicótica se subdivide, para a autora, em: negação total e negação parcial. A negação total diz respeito a negar a gestação até o parto e a negação parcial se refere à situação em que uma mulher descobre a gestação somente após o primeiro trimestre. Ressalta-se que a autora não inclui a dissimulação da gravidez, ou affective denial, conforme entendimento de Miller (2003), como uma entidade própria no campo das negações da gestação, incluindo-a, no entanto, como secundária em casos de negação não psicótica.

Dayan, Andro e Dugnat (1999) classificam os diferentes tipos de negação da gravidez por meio da proposição de polos, um consciente e outro inconsciente. $\mathrm{Na}$ extremidade consciente estaria presente a dissimulação da gravidez, já, na extremidade inconsciente, ocorreria a ação do mecanismo de defesa da recusa da realidade, o qual poderia ocorrer com mulheres com ou sem o diagnóstico de esquizofrenia.

Por mais que haja diferença para os autores no que diz respeito às nomenclaturas e à descrição dos tipos de negação da gravidez, podese perceber que, de maneira geral, há uma uniformidade no que 
tange ao entendimento de cada uma dessas formas: a dissimulação da gravidez está relacionada à consciência da gravidez, a negação em mulheres sem diagnóstico de psicose, à inconsciência do processo gestacional, e a negação psicótica está associada a uma situação de ruptura com a realidade.

No entanto, especificamente em relação à negação não psicótica da gravidez, percebe-se que não há um consenso no que diz respeito aos parâmetros de definição de um tempo mínimo, para que um caso seja considerado como pertencente a tal situação. O tempo mínimo varia entre os autores: três meses (Grangaud, 2001; Chaulet, 2011); 20 semanas (Wessel et al., 2002; Dayan et al., 2009), e seis meses (Pierronne, Delannoy, Florequin, \& Libert, 2002).

\section{Especificidades do fenômeno da negação não psicótica da gravidez}

Por contradizer o que, comumente, se sabe sobre um processo gestacional típico, a situação de uma gestação desconhecida apresenta múltiplas singularidades. Dentre essas particularidades, destaca-se a negação do entorno familiar e do corpo médico. Em relação aos familiares, Brezinka (2009) utiliza-se da descrição de folie à deux, ao considerar que uma loucura a dois se instala entre a filha que não sabia que estava grávida e a mãe que desconhecia o estado gravídico da sua filha, no sentido de que tanto a filha como a mãe reforçam a negação uma da outra, ao dizerem frases como "eu acreditava estar grávida, mas como a minha mãe nunca disse nada...", ou "eu suspeitei que a minha filha pudesse estar grávida, mas como ela nunca disse nada a respeito disso...". Chaulet (2011) afirma que a negação por parte do entorno reforça a racionalização da mulher de que seus sintomas não são oriundos de uma possível gravidez.

No que se refere à negação por parte dos médicos, Grangaud (2001) ressalta que alguns médicos podem não examinar a mulher de forma atenta ou não investigar profundamente as queixas que a paciente apresenta, pressupondo, assim, que toda mulher sabe quando está grávida (Grangaud, 2001). Beier, Wille e Wessel (2006) asseveram que cerca de $38 \%$ das mulheres de sua pesquisa consultaram um médico durante a gestação desconhecida, sem nunca terem recebido o diagnóstico de uma gravidez. Ademais, os autores afirmam que muitas mulheres reportam uma suposta menstruação durante 0 processo gestacional desconhecido, o que certamente pode dificultar o diagnóstico.

Nessa direção, Wessel e Endikat (2005) investigaram esse sangramento que é confundido pelas mulheres que passaram por essa experiência como advindo da menstruação. Para tanto, 
amostras de sangue para uma avaliação hormonal foram feitas até 144 horas após o parto de 28 participantes. Esse grupo foi comparado com um grupo de controle de 126 mulheres saudáveis com gestação transcorrida normalmente e que tiveram parto normal. Após diversas avaliações hormonais, concluiu-se que os padrões hormonais avaliados imediatamente após o parto em mulheres que desconheciam sua gestação não resultaram em nenhuma explicação causal. Assim, a explicação para essa suposta menstruação não pode ser entendida a partir de uma perspectiva de mecanismos endocrinológicos. I. Nisand (Comunicação pessoal, $1^{0}$ de agosto de 2013) assevera que tal sangramento pode ser entendido na mesma lógica que o fenômeno da gravidez psicológica, em que há a presença de sintomas típicos de gestação, mesmo sem a mulher estar grávida. Para o autor, na negação não psicótica da gravidez ocorre algo semelhante, uma vez que a mulher pode manifestar sinais que confirmem que ela não esteja grávida, como, por exemplo, a presença do ciclo menstrual.

Nesse sentido, um outro sintoma típico da gestação que não se apresenta e que pode levar a mulher a não suspeitar que esteja grávida é a dilatação do ventre. Nessa condição, o útero se desenvolve para trás, fazendo com que o bebê se desenvolva ao longo da coluna vertebral e não para frente, como comumente observado (Navarro, 2009). I. Nisand (Comunicação pessoal, 10 de agosto de 2013) explica que, em situações de negação da gravidez, ao invés de o feto se expandir horizontalmente, ele se expande verticalmente em direção ao diafragma materno, possibilitando com que a mulher não apresente a característica barriga de grávida. Ainda sobre a dilatação do ventre, quando uma gestação é descoberta antes do parto pela própria mulher, familiares ou médicos, a gestante pode, em poucos dias, apresentar a dilatação do ventre e sentir os movimentos intrauterinos, explicitando, em tão pouco tempo, uma verdadeira metamorfose física (Rozan, 2008; Navarro, 2009; Sandoz, 2011).

Outra especificidade observada sobre a experiência de gestação desconhecida é a impossibilidade de nomeação ao bebê que até então era desconhecido para a mãe. Em muitas situações, mulheres que passaram por essa experiência ficam dias sem conseguir nomear 0 seu filho, pedindo para que um parente, amigo ou profissional de saúde escolha o nome do recém-nascido. Em outras circunstâncias, o nome do filho é escolhido em homenagem ao médico que realizou o parto ou à enfermeira que a auxiliou (Brezinka, Huter, Bielb, \& Kinzl, 1994; Chaulet, 2011). Além disso, a relação mãe-bebê após o parto pode se mostrar difícil. Brezinka et al. (1994) acompanharam quatro crianças que nasceram sob condição de negação da gravidez. Esse acompanhamento se deu até os dois anos de idade das crianças. Os autores observaram que três das crianças foram postas para adoção 
ou estavam sendo cuidadas por suas avós. Ressalta-se, no entanto, que não é possível fazer uma relação linear e exclusiva entre o fenômeno e situações de maltrato (Brezinka et al., 1994; Pierronne et al., 2002; Chaulet, 2011).

Os poucos estudos acerca da relação mãe-bebê em situações de negação não psicótica da gravidez não exploram aspectos mais sutis que circulam nessa interação primordial. Nota-se, também, uma falta de investigação sobre as repercussões psíquicas na criança. Certamente, este é um campo de estudos que merece ser mais bem explorado.

\section{Outras explicações teóricas para o fenômeno}

As explicações para a situação em que uma mulher não percebe a sua própria gestação são diversas. Seguin (2011) assevera que o estudo da negação da gravidez implica em muitos questionamentos. A autora indaga sobre qual seria o objeto alvo da negação: o bebê? a ideia de ser mãe? a capacidade de procriação? a feminilidade? a relação sexual? a sexualidade? o fato de estar grávida? o corpo? Esses questionamentos mostram possibilidades de pesquisa e a diversidade de pontos para os quais os teóricos podem direcionar seus estudos sobre esse fenômeno.

Para alguns autores, a negação de uma gestação tem relação com fatores protetivos e adaptativos. Ferragu (2002) sustenta a ideia de que a negação da gravidez é um meio do qual as mulheres se utilizam para não terem que lidar com todas as angústias que uma gravidez geralmente suscita, possibilitando, ao mesmo tempo, que elas continuem a desempenhar suas atividades profissionais e pessoais, sem que uma gestação comprometa o seu cotidiano e seus projetos futuros. Pierronne et al. (2002) afirmam que a negação da gravidez traz em seu bojo um caráter econômico em que haveria a possibilidade de existir um desejo inconsciente de ter um filho, porém sem ter que enfrentar as consequências sociais e profissionais comumente associadas a uma gestação.

Giudice (2007) entende a negação da gravidez através de uma perspectiva da biologia evolucionária. O autor nomeia e entende o fenômeno como uma situação de cryptic pregnancy (gravidez encriptada). Nesse contexto são lançadas três hipóteses para entender o porquê de uma mulher não saber que está grávida. A primeira diz respeito a uma solução não adaptativa advinda de processos de resolução de conflito em relação à alocação de recursos na gestação, que possivelmente estão relacionados a interrupções menores dos mecanismos de imprinting genômico. Essa hipótese lança a ideia de que uma gravidez encriptada - termo utilizado por Giudice (2007) - possibilitaria à mulher experienciar uma gestação 
sem se implicar nas mudanças físicas que uma gravidez requer e sem se envolver também com as mudanças sociais que um estado gravídico acarreta. A segunda hipótese se refere à situação de que uma gravidez encriptada possa ser em sua origem uma falha na tentativa do organismo de abortar fetos inviáveis, isto é, fetos que não sobreviveriam fora do útero. A terceira e última hipótese se relaciona com uma situação de "cooperação forçada" entre o feto e a mãe, quando ambos estão submetidos a um ambiente estressante e ameaçador, permitindo, em um contexto como tal, uma melhor taxa de sobrevivência para a mãe e para o bebê até o parto.

J. Wessel (Comunicação pessoal, 16 de julho de 2013) entende a negação da gravidez como a única maneira que uma mulher possui para engravidar e ter um filho. O autor cita um caso clínico de uma paciente que foi alertada pelo seu médico de que, caso engravidasse, poderia desenvolver o mesmo problema de saúde que tirou a vida do seu pai. Após esse fato, a gravidez ficou associada a uma possível morte. A única forma encontrada pela paciente para satisfazer seu desejo de maternidade foi negando a gestação até o momento do parto.

Wrobel (2002) afirma que a negação da gravidez é uma forma pela qual a mulher anula e invalida a ambivalência em relação ao desejo de ter um filho, permitindo, dessa maneira, que as fantasias infanticidas não se manifestem, sendo então este fenômeno um mecanismo de proteção tanto para a mãe quanto para o bebê. Assim, ao não saber sobre a sua própria gestação, a mãe estaria poupando tanto ela quanto o filho de consequências mais drásticas para ambos, como o infanticídio.

Darchis (2007) assevera que a negação da gravidez pode trazer consigo questões relacionadas à transmissão transgeracional. A autora acompanhou uma paciente que negou a gestação até o quinto mês. Essa paciente nasceu após a morte misteriosa de uma irmã em um tempo anterior. Os pais lhe deram o mesmo nome de sua irmã que havia falecido. A autora entende que a negação da gravidez pode estar associada a uma tentativa de troca de identidade com um objeto morto. Ao fazer essa identificação, a negação da gravidez serviria, como no caso da paciente, como uma forma de extinguir as linhas de descendência com os comportamentos suficientemente traumáticos das gerações precedentes.

A associação entre negação da gravidez e uma sexualidade traumática é abordada por alguns autores. Bonnet (1993) propõe uma linha de raciocínio explicativa para o fenômeno que tem sido amplamente difundida e utilizada entre aqueles que se dedicam a estudar este tipo de situação. A autora afirma que na história de vida de mulheres que negaram a gestação há sempre uma vivência traumática de cunho sexual, como, por exemplo, um abuso por parte de algum parente, uma história de incesto ou questões que vão 
além de um abuso real, como em casos de pais que adotam perante os filhos atitudes paradoxais em relação à sexualidade, isto é, por um lado reprimem e proíbem assuntos relacionados à sexualidade, porém, por outro, se comportam de maneira sexualizada com os filhos.

A partir desses traumas vividos na infância ou na vida recente de uma mulher, a sexualidade fica impossibilitada de ser exercida. Bonnet (1993) afirma que a gestação passa a representar uma expressão da sexualidade que carrega consigo a marca das vivências traumáticas daquilo que foi vivenciado em um tempo anterior. A negação de uma gestação não viabilizaria, dessa forma, que essa vivência emergisse na consciência da mulher, trazendo, dessa maneira, o que foi experienciado como trauma. A negação da gravidez é acompanhada também de uma negação da fecundidade e de uma negação do potencial procriativo. Assim, a relação sexual está dissociada da possibilidade de procriação, como se um ato sexual não pudesse resultar em uma gestação. A autora nomeia essa dinâmica como gravidez impensável, pois, ao vivenciar experiências sexuais traumáticas, a mulher despotencializa o exercício da genitalidade, logo uma expressão desse exercício (gravidez) se presentifica como algo impossível de ocorrer.

Nessa linha de raciocínio, Bayle (2005) assevera que a negação da gravidez é a negação de um bebê que teve sua origem advinda de uma relação sexual marcada pelo incesto, por um estupro ou por uma relação extraconjugal. $O$ ato sexual passa a ser uma representação perturbadora que precisa ser negada e expulsa do psiquismo. O autor afirma que na negação da gravidez há uma vivência traumática que prejudica a conjugalidade, a sexualidade e a procriação, impossibilitando estas mulheres de construírem vias saudáveis para suas vidas.

\section{A frequência do fenômeno da negação não psicótica da gravidez e as suas possíveis consequências}

O principal estudo que demonstra que a negação não psicótica da gravidez não é um fenômeno raro diz respeito à pesquisa desenvolvida por Wessel et al. (2002) na Alemanha, se tratando da primeira investigação prospectiva e epidemiológica acerca dessa situação. A pesquisa foi realizada de 10 de julho de 1995 até 30 de junho de 1996, e durante esse período os pesquisadores visaram conhecer quantas mulheres na Região Metropolitana de Berlim haviam negado a sua própria gestação, seja parcial ou totalmente. Todas as instituições da região metropolitana foram informadas sobre a pesquisa, devendo reportar aos pesquisadores casos de negação da gravidez que tivessem ocorrido naqueles locais. Após um ano de 
pesquisa, verificou-se que 65 mulheres sem diagnóstico de psicose haviam negado seu próprio estado gravídico. A partir desse dado inicial, pôde-se ter acesso a outras informações acerca dessas mulheres, principalmente no que se refere a dados sociodemográficos e à possibilidade de estabelecer uma frequência desse fenômeno em Berlim e estimar a frequência na Alemanha, baseando-se na ocorrência anual de nascimentos naquele país. Alguns dados sociodemográficos mostram que, das 65 mulheres, $90 \%$ delas tinham entre $19-41$ anos, sendo a idade média 27 anos, a mulher mais nova da pesquisa tinha 15 e a mais velha, 44 anos. Em relação ao estado civil, 54 das 65 mulheres viviam com algum parceiro e 36 mulheres, do total da amostra, tiveram pelo menos uma gestação prévia. No que diz respeito aos recém-nascidos, surpreende o fato de que, das 69 crianças nascidas, oito recémnascidos eram advindos de gestações gemelares (Wessel et al., 2002). A partir desses dados, pode-se pensar que a negação não psicótica da gravidez não ocorre prioritariamente com adolescentes, primíparas e mulheres solteiras. Wessel et al. (2002), após terem coletado esses dados, puderam, dessa forma, determinar a frequência do fenômeno no contexto estudado. No ano em que essa pesquisa foi realizada, ocorreram 29.462 partos nos mesmos hospitais em que se executou a pesquisa, possibilitando assim uma frequência de um caso de negação não psicótica da gravidez em sua forma parcial ou total a cada 475 nascimentos, e, se considerando apenas a forma total, a frequência é de um caso para 2455 nascimentos. Os autores ainda projetaram uma estimativa para toda a Alemanha a partir dos resultados obtidos na pesquisa. Sendo assim, ocorreriam 1600 casos de negação parcial e total, e 80 casos de negação total por ano. A conclusão dos autores é que a negação não psicótica da gravidez não pode ser mais considerada como algo raro e exótico.

Outro estudo que demonstra que esse fenômeno não é raro é a pesquisa retrospectiva feita por Brezinka et al. (1994) na região de Tirol, na Áustria, durante o período compreendido entre 1987 e 1990. Durante esse período, ocorreu um caso de negação não psicótica da gravidez a cada 400 gestações, se forem considerados apenas os casos de negação descobertos entre as 21 e 32 semanas de gestação; para estados gravídicos descobertos após as 32 semanas de gestação, a frequência foi de um caso para 2500 gestações. Friedman, Heneghan e Rosenthal (2007) também conduziram uma pesquisa retrospectiva, durante 0 período compreendido entre janeiro de 1997 e dezembro de 2003, com mulheres que tiveram seus filhos em uma instituição hospitalar sem nunca terem feito acompanhamento pré-natal. Dos 31.475 nascimentos durante esse período, 216 partos não tiveram assistência pré-natal prévia. Estes 216 partos ocorreram em 211 mulheres, e 61 destas preencheram 
os critérios para a negação não psicótica da gravidez. Com essa pesquisa, apesar das limitações em relação ao método, os autores estimam que a negação não psicótica da gravidez nas suas formas parcial e total ocorram em uma frequência de um caso a cada 500 nascimentos nos Estados Unidos.

Nirmal, Thijs, Bethel e Bhal (2006) realizaram uma pesquisa retrospectiva no País de Gales entre 1989 e 1999 para saber quantas mulheres sem acompanhamento pré-natal haviam apresentado negação não psicótica da gravidez. Os autores estimam, a partir dos prontuários disponíveis nos hospitais de South Glamorgan, que esse fenômeno acontece em uma frequência de um caso de negação total para 2500 nascimentos.

Baseados nos estudos de Wessel et al. (2002) e Nirmal et al. (2006), Navarro, Decroix e Godeau (2011) estimam que na França esse fenômeno ocorreria na frequência de 1600 casos de negação parcial e 330 casos de negação total por ano. Pierronne et al. (2002), em sua pesquisa prospectiva entre os anos de 1993 e 2000, na parte norte da França, apresentam outra frequência. Para os autores, a negação total da gestação ocorreria em um caso a cada 1000 nascimentos, sendo, dessa forma, mais frequente quando comparada à estimativa apresentada por Navarro et al. (2011). Essa diferença pode ser resultante dos distintos contextos e períodos de tempo pesquisados.

Quando comparada a certas situações obstétricas, Wessel et al. (2002) afirmam que a negação não psicótica da gravidez é mais frequente na Alemanha do que a doença hemolítica e a apendicite aguda. A negação total da gestação é três vezes mais frequente que o nascimento de trigêmeos, além de ter a mesma frequência que a eclâmpsia. Os autores asseveram que o que poderia ser considerado como raro hoje em dia é o fenômeno que seria o oposto da negação não psicótica da gravidez, ou seja, a gravidez psicológica ou pseudociese.

Em relação às consequências que uma gestação desconhecida pode trazer, os dados obtidos por Wessel et al. (2002) revelam que esse fenômeno demonstra um aumento de risco neonatal estatisticamente significativo. Para tal comprovação, os autores compararam os dados de sua pesquisa com os dados estatísticos da população perinatal da Alemanha. Sendo assim, chegaram à seguinte comparação: nascimento de bebês com peso inferior a 2500 $\mathrm{g}, 18 \%$ contra $6 \%$ da população em geral; presença de quadro de retardo mental: $27 \%$ em casos de negação não psicótica da gravidez versus $8 \%$; mortalidade elevada, maior em $1,5 \%$ quando comparada à população geral; frequência maior de partos prematuros: $16 \%$ versus $6 \%$. Além disso, por não saberem que estão grávidas, as mulheres nessa condição podem fazer uso de drogas, tabaco, álcool, adotarem comportamentos e posturas de risco, além de se exporem a procedimentos danosos como o exame de raio- $x$. Todas essas 
questões podem impactar diretamente na saúde do bebê.

Entretanto, a consequência mais radical advinda de uma situação em que a mulher nega a sua gestação é o neonaticídio. O termo "neonaticídio" foi cunhado por Resnick (1969) para descrever as situações em que a mãe ou o pai ou ambos matam seu filho nas primeiras vinte e quatros horas de vida do recém-nascido. Chaulet (2011) aponta para a possibilidade de uma mulher, ao descobrir sua gestação somente na hora do parto, matar o seu filho recémnascido. A mulher estando sozinha durante o parto pode ser invadida pelo pânico e pela intensidade daquela situação e matar o bebê. As formas mais comuns de morte apontadas por Resnick (1969) são o afogamento, pois essas mulheres descobrem que estão grávidas no vaso sanitário, ou por sufocamento, pois, logo após o parto, ao ouvirem o choro do bebê, elas entram em desespero e tentam calar a prova real de que deram à luz um bebê.

\section{Considerações finais}

Este artigo teve como objetivo apresentar uma revisão de literatura sobre o fenômeno da negação não psicótica da gravidez, mostrando os diferentes aspectos acerca dessa experiência. Essa proposta é fundamental, haja vista a necessidade de saber e conhecer os pontos que já foram explorados, quais aspectos precisam ser mais aprofundados e quais situações precisam ainda de investigação científica. Sendo assim, percebe-se que os parâmetros de definição sobre um tempo mínimo para que um caso seja considerado como pertencente à situação de negação não psicótica da gravidez não possui um consenso na literatura. Para avançar o conhecimento é essencial que aqueles que se dedicam a esta temática cheguem a um denominador comum, pois isso auxiliaria nas comparações entre as diferentes pesquisas.

A pesquisa sobre a relação mãe-bebê precisa ser mais bem explorada, isto é, um acompanhamento sistemático e prolongado dessa relação, utilizando métodos de observação mãe-bebê para investigar a qualidade na relação entre essa dupla. Mostramse importantes, também, investigações acerca das etapas do desenvolvimento dessas crianças, por exemplo, questões esperadas ao longo do desenvolvimento ou relativas à aprendizagem, a fim de obter dados que mostrem, ou não, diferenças significativas quando comparadas a crianças que não nasceram sob tal condição.

Outro ponto que deveria ser mais bem compreendido é a relação dessas mulheres com as suas próprias mães e com os seus parceiros. Poderia ser interessante realizar entrevistas com as suas mães e com os seus cônjuges a fim de saber mais sobre a dinâmica familiar e aspectos concernentes à negação do entorno. Além disso, mais 
pesquisas epidemiológicas seriam de extrema relevância, para que, assim, se tenha mais dados de outras regiões do mundo, o que possibilitaria a comparação dos dados de diferentes lugares.

Investigações advindas de um processo analítico ou de uma psicoterapia com longa duração nunca foram alvo de pesquisa. Um processo psicoterápico prolongado seria interessante na medida em que disponibilizaria dados mais aprofundados sobre a história de vida dessas mulheres, além de fomentar e enriquecer o arcabouço teórico sobre a gestação desconhecida. Intervenções com profissionais de saúde também são necessárias, pois objetivariam a consciência desses profissionais sobre o fenômeno, possibilitando assim uma via preventiva e de promoção de saúde.

A negação não psicótica da gravidez é uma temática que nunca se esgota, justamente por trazer em seu cerne a complexidade inerente à vida humana. Esforços de compreensão desse fenômeno devem ser feitos para que se tenha um auxílio possível à mãe e ao bebê que passam por essa experiência, retirando-os desse lugar de extremo risco.

\section{Referências}

AFRDG. (2009). Déni de grossesse: 99 histoires vécues. Nantes: Amalthée.

Bayle, B. (2005). L' enfant à naître. Paris: Eres.

Beier, K., Wille, R., \& Wessel, J. (2006). Denial of pregnancy as a reproductive dysfunction- A proposal for international classification systems. Journal of psychosomatic Research, 61(5), 723-730.

Bonnet, C. (1993). Adoption at birth: Prevention against abandonment or neonaticide. Child Abuse \& Neglect, 17(4), 501-513.

Brezinka C., Huter O., Bielb W., \& Kinzl J. (1994). Denial of pregnancy: Obstetrical aspects. Journal of Psychosomatic Obstetrics \& Gynecology 15, 1-8.

Brezinka C. (2009). A propos des données épidémiologiques. In Actes du premier colloque français sur le déni de grossesse (pp. 1523). Toulouse: Ed Universitaires du Sud.

Chaulet, S. (2011). Deni de grossesse: exploration Clinique et psychopathologique, prise en charge étude retrospective sur 5 ans au chu d'angers. Tese de doutorado não publicada. Université d'Angers, Angers.

Darchis, E. (2007). Déni de Grossesse: la part des âncestres. Divan Familial 18, 105-121.

Dayan, J., Andro, G., \& Dugnat, M. (1999). Psychopatologie de la périnatalité. Paris: Masson. 
Ferragu, G. (2002). Le déni de grossesse : une revue de litterature Tese de doutorado não publicada. Université de Rennes I, Rennes.

Friedman, S. H., Heneghan, A., \& Rosenthal, M. (2007). Characteristics of women who deny or conceal pregnancy. Psychosomatics, 48, 117-122.

Giudice, M. (2007). The evolutionary biology of criptic pregnancy: a re-apraisal of the denied pregnancy phenomenon. Medical Hypotheses, 68, 250-258.

Gonçalves, T. (2014). O desempoderamento da gravidez: implicações psíquicas em mulheres que não sabiam que estavam grávidas até o momento do parto. Dissertação de Mestrado não publicada. Pontifícia Universidade Católica do Rio Grande do Sul, Porto Alegre, RS, Brasil.

Grangaud, N. (2001). Déni de grossesse: description clinique et essai de compréhension psychopathologique.Tese de doutorado não publicada, Université Paris VII, Paris, France.

Kaplan, R., \& Grotowski, T. (1996). Denied pregnancy. Australian and New Zealand Journal of Psychiatry, 30, 861-863.

Labarthe, S. (1988). Le déni de grossesse. Tese de doutorado não publicada. Université de Bordeaux, Bordeaux, France.

Miller, L.J. (2003). Denial of pregnancy, in infanticide: Psychosocial and Legal perspectives on mothers who kill. Edited by Spinelli, M.G. Washington DC, American Psychiatric Publishing Inc, 81104.

Milstein, K.K., \& Milstein P.S. (1983). Psychophysiologic aspects of denial in pregnancy: Case Report. Journal of Clinical Psychiatry, 44(5), 189- 190.

Navarro, F. (2009). Negación del embarazo, una enfermedad misteriosa. Acesso em 5 de junho de 2011. Recuperado em, 5 de junho, 2011, de: http://www.rfi.fr/actues/articles/114/ article_12068.asp

Navarro, F., Decroix, M., \& Godeau, E. (2011). Le déni de grossesse à l'adolescence. Revista de Psicologia da Criança e do adolescente, 3, 147-164.

Nirmal, D., Thijs, I., Bethel, J., \& Bhal, P.S. (2006) The incidence and outcome of concealed pregnancies among hospital deliveries: An 11-year population-based study in South Glamorgan. Journal of Obstetrics and Gynaecology, 26(2), 118-121.

Pierronne, C., Delannoy, M. A., Florequin, C., \& Libert M. (2002). Le déni de grossesse: à propos de 56 cas observés en maternité. Perspectives Psy, 41(3), 182-188.

Resnick, P. (1969). Child murder by parents: a psychiatric review of filicide. American Journal of Psychiatry, 126, 325-334.

Rozan, M. (2008). L'obstétricien et le déni de grossesse, Actes du premier colloque français sur le déni de grossesse, 41-45. 
Sandoz, P. (2011). Reactive-homeostasis as a cybernetic model of the silhouette effect of denial of pregnancy. Medical Hypotheses, 77, 782-785.

Seguin, S. (2011). Les denis et les negations - Une voie de dégagement de l'emprise maternelle. Tese de Doutorado não publicada. Université Paris-Descartes, Paris, France.

Slayton, R., \& Soloff, P. (1981). Psychotic denial of third trimester pregnancy. Journal of Clinical Psychiatry, 42(12), 471-473.

Wessel J., Endrikat J., \& Buscher, U. (2002). Frequency of denial pregnancy: results and epidemiological significance of a one-year prospective study in Berlin. Acta Obstetricia et Gynecologica Scandinavica, 81, 1021-1027.

Wessel. J., \& Endrikat, J. (2005) Cyclic menstruation-like bleeding during denied pregnancy. Is there a particular hormonal cause? Gynecological Endocrinology, 21(6), 352-359.

Wrobel, G. (2002). Premières traces: vers un carnet de vie. Paris: Eres Robin.

\section{Endereço para correspondência Thomás Gomes Gonçalves}

Universidade Federal do Rio Grande do Sul

Programa de Pós-graduação em Psicologia

Instituto de Psicologia da Universidade Federal do Rio Grande do Sul

Rua Ramiro Barcelos, 2600 sala 108, CEP 90035-003, Porto Alegre - RS, Brasil

Endereço para correspondência: gomes.thomas@gmail.com

Recebido em: 23/04/2014

Reformulado em: 06/10/2014

Aceito para publicação em: 11/10/2014

\section{Notas}

* Psicólogo. Membro do Centro de Estudos Psicanalíticos de Porto Alegre (CEPdePA) - Psicanalista em Formação. Mestre em Psicologia Clínica pela Pontifícia Universidade Católica do Rio Grande do Sul (PUCRS). Doutorando em Psicologia pelo Programa de Pós-graduação da Universidade Federal do Rio Grande do Sul (UFRGS). Membro da Association Française pour la reconnaissance du Déni de Grossesse (Toulouse- França). Membro da Comissão Editorial da Revista Diaphora da Sociedade de Psicologia do Rio Grande do Sul. 